\title{
Risk Stratification of Acute Pulmonary Embolism and Determining the Effect on Chronic Cardiopulmonary Complications: The REACH Study
}

\author{
Hannah Stevens ${ }^{1,2,3}$ Wendy Fang ${ }^{2}$ Warren Clements ${ }^{4,5}$ Jason Bloom ${ }^{2,6}$ James McFadyen ${ }^{1,2,3}$ \\ Huyen $\operatorname{Tran}^{1,2}$
}

${ }^{1}$ Department of Haematology, Alfred Hospital, Melbourne, Victoria, Australia

2 Department of Medicine, Monash University, Melbourne, Victoria, Australia

${ }^{3}$ Atherothrombosis and Vascular Biology Program, Baker Heart and

Address for correspondence Hannah Stevens, MBBS, FRACP, FRCPA, Department of Haematology, Alfred Hospital, 55 Commercial Road, Melbourne, Victoria 3000, Australia

Diabetes Institute, Melbourne, Victoria, Australia

${ }^{4}$ Department of Radiology, Alfred Hospital, Melbourne, Victoria,

Australia

${ }^{5}$ Department of Surgery, Monash University, Melbourne, Victoria, Australia

6 Department of Cardiology, Alfred Hospital, Melbourne, Victoria, Australia (e-mail: Hannah.stevens1@monash.edu).

TH Open 2020;4:e45-e50.

\author{
Abstract \\ Keywords \\ - pulmonary embolism \\ - risk stratification \\ - venous \\ thromboembolism \\ - pulmonary \\ hypertension \\ - thrombosis
}

Introduction Patients with acute pulmonary embolism (PE) are at risk of developing chronic complications including the post-PE syndrome with reduced cardiopulmonary function and chronic thromboembolism pulmonary hypertension (CTEPH). Risk stratification at PE diagnosis is an important tool in predicting early mortality; however, its use in predicting chronic complications has not been evaluated.

Objective This study investigates the effect of initial risk stratification of intermediate risk and standard risk PE on the rate of development of chronic complications including right ventricular (RV) dysfunction, residual perfusion defects, and CTEPH.

Methods Cases of acute PE $(n=1,524)$ were identified using International Statistical Classification of Diseases and Related Health Problems, Tenth Revision, Australian Modification discharge diagnosis coding for PE. Evidence of RV dysfunction and systolic blood pressure $<90 \mathrm{~mm} \mathrm{Hg}$ were used to risk stratify into high, intermediate and standard risk PE.

Results There were 508 patients included in the analysis. Intermediate risk PE was associated with higher rates of persistent RV dysfunction as well as residual perfusion defects on repeat imaging. The overall rate of CTEPH was low (0.6\%) and there was no difference between the intermediate risk and standard risk PE groups.

Conclusion These findings demonstrate that acute intermediate risk PE is associated with higher rates of RV dysfunction on follow-up imaging than standard risk PE. However, the rate of CTEPH was similar between the two groups and overall the CTEPH rate was low among all patients with intermediate and standard risk PE. received

November 27, 2019

accepted

February 14, 2020
DOI https://doi.org/

10.1055/s-0040-1708558. ISSN 2512-9465.
(C) 2020 Georg Thieme Verlag KG Stuttgart · New York
License terms

(c) (1) 


\section{Introduction}

Acute venous thromboembolism (VTE), including both deep vein thrombosis and pulmonary embolism (PE), is a commonly diagnosed medical condition with an incidence of approximately 1 to 1.5 per 1,000 person-years. ${ }^{1-3}$ Importantly, VTE is associated with significant morbidity and mortality, and in particular acute PE is an independent predictor of reduced survival. ${ }^{1,4,5}$ Clinical research has often focused on the evaluation of diagnosis and treatment of acute PE; however, there remains a relative lack of evidence concerning the determinants of long-term outcomes among patients with PE.

The post-PE syndrome is a recently described entity and encompasses a collection of signs and symptoms that persist following acute PE. Although no formal definition yet exists, this syndrome may include components such as suboptimal cardiac function, pulmonary artery flow dynamics or pulmonary gas exchange in combination with persistent dyspnoea, reduced exercise tolerance and diminished quality of life, without an alternative explanation. ${ }^{6}$ Prospective research has demonstrated that $44 \%$ of patients suffering from an acute PE are described having a New York Heart Association (NYHA) heart failure score of II or higher at least 6 months after PE diagnosis. ${ }^{7}$ Furthermore, nearly half of all patients have exercise limitation at 1 -year post-PE diagnosis as measured by peak oxygen uptake on cardiopulmonary exercise testing. These functional limitations significantly impact those affected with a reduction in health-related quality of life. ${ }^{8}$

In addition to the post-PE syndrome, the most notorious chronic complication of acute PE is chronic thromboembolic pulmonary hypertension (CTEPH). CTEPH is defined by residual thrombus on radiological imaging and evidence of raised pulmonary pressures on right heart catheterization. ${ }^{9}$ The incidence of CTEPH is estimated to be between 0.4 and $9.1 \%$ in the 2 years following an acute $\mathrm{PE},{ }^{10-16}$ but at present it is difficult to determine which patients will develop this debilitating disease. Medical risk factors that may predispose to the development of CTEPH include a larger initial perfusion defect, prior VTE, presence of anti-phospholipid antibodies or prior splenectomy. ${ }^{10,17-19}$ The prompt recognition of CTEPH and instigating early treatment is a critical factor in its management since it remains a potentially 'curable' condition by way of a pulmonary endarterectomy, which can dramatically improve symptoms of dyspnoea. $^{20,21}$ This is underscored by the fact that if CTEPH remains undiagnosed or untreated, the 5-year survival is approximately $30 \%$ and is associated with a marked increase in morbidity and a detrimental effect on quality of life. ${ }^{22}$

\section{Methods}

\section{Study Design}

A retrospective, observational study conducted at a tertiary referral institution. Ethics approval was obtained from the local human research ethics committee (project number 90/18).

\section{Population}

All patients receiving inpatient management for acute symptomatic PE between January 2012 and July 2017.

\section{Eligibility Criteria}

All patients with a diagnosis of acute PE treated at our centre were eligible for inclusion. Patients were excluded if: age $<18$ years, known prior right ventricular (RV) dysfunction or conditions judged by the investigators to cause RV dysfunction from severe prior cardiopulmonary pathology. Additionally, we excluded isolated sub-segmental PE or high-risk PE (PE with systolic blood pressure less than $90 \mathrm{~mm} \mathrm{Hg}$ for 15 minutes or more and RV dysfunction). Importantly, all patients with less than 6 months' follow-up were excluded, except those who underwent earlier radiological imaging showing no evidence of residual PE. A flowchart of the study population is shown in -Fig. 1.

\section{Identification of Cases}

Hospital discharge records were interrogated using the International Statistical Classification of Diseases and Related Health Problems, Tenth Revision, Australian Modification (ICD-10-AM) codes corresponding to the diagnosis of acute PE.

\section{Risk Stratification}

Following initial identification, electronic medical records, radiology reports and transthoracic echocardiogram (TTE) results were then reviewed by the study investigators to confirm the diagnosis and classify acute PE into standard, intermediate and high-risk PE according to criteria adapted from the European Society of Cardiology's Guidelines on the diagnosis and management of acute pulmonary embolism shown in - Table $1 .^{23}$

\section{Definitions for Right Heart Dysfunction and CTEPH}

$\mathrm{RV}$ dysfunction was defined as either:

1. TTE measurements of RV size using RV basal diameter or RV systolic dysfunction using tricuspid annular plane systolic excursion from the American Society of Echocardiography and European Society of Cardiovascular Imaging Recommendations for cardiac chamber quantification by echocardiography in adults. ${ }^{24}$

2. Computed tomographic pulmonary angiography (CTPA) demonstrating a right ventricle to left ventricle ratio of greater than 0.9 on radiologist review. CT criterion was only used if TTE was not performed at diagnosis.

The diagnosis of suspected pulmonary hypertension was based on TTE using tricuspid regurgitation velocity. Confirmed CTEPH was diagnosed on right heart catheterization using the European Society of Cardiology and European Respiratory Society Guidelines for the diagnosis and treatment of pulmonary hypertension. ${ }^{25}$

\section{Follow-up}

Cases were followed for at least 6 months. Repeat radiological imaging or TTE was performed at physician discretion based on patient symptoms. Chronic complications reviewed on follow-up imaging included persistent RV dysfunction, residual thrombus and CTEPH. 


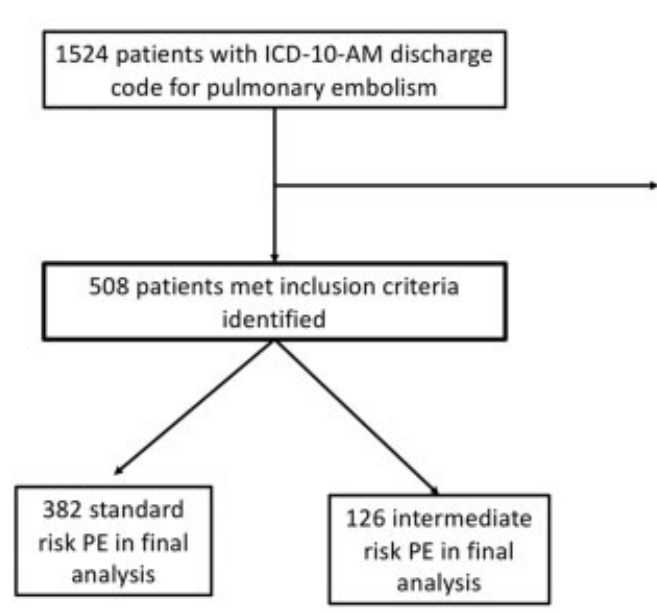

Fig. 1 Flowchart for inclusion and exclusion criteria.

Table 1 Risk stratification of acute pulmonary embolism ${ }^{23}$

\begin{tabular}{|l|l|l|}
\hline Risk & $\begin{array}{l}\text { Shock or } \\
\text { hypotension }\end{array}$ & $\begin{array}{l}\text { Right ventricular } \\
\text { dysfunction }\end{array}$ \\
\hline Standard & Absent & Absent \\
\hline Intermediate & Absent & Present \\
\hline High & Present & Present \\
\hline
\end{tabular}

\section{Statistical Methods}

Data was collected using Excel. Statistical significance was evaluated using Fisher's exact test and unpaired $t$-test, with a $p$-value of $<0.05$ regarded as statistically significant throughout.

\section{Results}

Initial review of all discharge diagnoses of acute PE using the ICD-10-Am classification identified 1,524 patients. Of these, 508 were eligible for inclusion in the final analysis (-Fig. 1). The general characteristics, treatment and follow-up for both groups are shown in - Table 2 . The median age, sex, weight and prior history of VTE were similar between the two groups. CTPA was used to establish the diagnosis of acute PE in the majority of patients in both the intermediate and the standard risk PE groups (95\% vs. 96\%, respectively) and the remainder of the patients were diagnosed using ventilation/perfusion lung imaging. Intermediate risk PE was associated with an increase in proximal extent of thrombus, with $48 \%$ of patients having thrombus in the saddle or main pulmonary arteries, in contrast to $19 \%$ in the standard risk group. TTE at diagnosis was performed in $82 \%$ of the intermediate risk group in comparison to $28 \%$ of the standard risk group.

The findings of the study are listed in - Table 3. A repeat TTE at least 3 months after acute PE diagnosis was performed in 36 (29\%) patients in the intermediate risk group and 84 (22\%) in the standard risk group at a median time of 10.8 months in both groups. The rate of persistent RV dysfunction identified on TTE was higher in the intermediate risk group compared with the standard risk group at 44 and $18 \%$,

\begin{tabular}{|ll|}
\hline \multicolumn{1}{|c|}{ Exclusions $(\boldsymbol{n = 1 0 1 6 )}$} & \\
No acute PE identified: & 364 \\
Less than 6 months follow-up & 358 \\
Previous right heart dysfunction & 120 \\
Prior severe cardiorespiratory & 72 \\
disorders & \\
VQ scan without TTE at diagnosis & 37 \\
Isolated subsegmental PE & 35 \\
Age less than 18 years & 18 \\
High risk PE & 12 \\
\hline
\end{tabular}

respectively ( $p=0.003$ ). Additionally, in the patient cohort that had repeat radiological imaging at least 3 months from diagnosis, residual perfusion defects were demonstrated in $40 \%$ of the intermediate risk group and $23 \%$ of the standard risk group $(p=0.04)$.

Overall, the rate of suspected CTEPH in the study was $0.6 \%$. CTEPH was suspected in 2 patients (1.6\%) in the intermediate risk group and 1 patient $(0.26 \%)$ in the standard risk group. However, due to medical comorbidities no patients in either group had CTEPH confirmed on right heart catheterization.

\section{Discussion}

In this study, we have determined that following acute PE a significant proportion of patients has persistent RV dysfunction on repeat TTE, which in turn supports the notion of the post-PE syndrome. The risk of persistent RV dysfunction is increased in patients with intermediate risk PE when compared with standard risk PE (44\% vs. $18 \%$, respectively). Despite this, a diagnosis of standard risk PE is still associated with nearly one in five patients developing RV dysfunction at least 3 months after diagnosis of acute PE. These findings are supported by previous work by Stevinson et al, who demonstrated in their prospective non-interventional study that $41 \%$ of patients developed RV dysfunction or had functional impairment 6 months after a diagnosis of acute, non-massive PE. ${ }^{7}$ This study did not, however, determine differences between standard and intermediate risk PE. Further, when evaluating the late complications from the PEITHO (Pulmonary Embolism Thrombolysis) trial, Konstantinides et al, demonstrated that $44 \%$ of patients with intermediate risk PE had persistent RV dysfunction with no difference between anticoagulation and thrombolysis. ${ }^{26}$ Additionally, a further post hoc analysis of the PEITHO trial suggested that $13 \%$ of those with intermediate risk PE had either post-PE syndrome or CTEPH when combining both echocardiographic findings and NYHA functional classification. ${ }^{27}$ However, direct comparison of the functional and radiological measures in these trials should be performed with caution due to differences in the definitions of outcome measures. 
Table 2 Baseline characteristics of study population

\begin{tabular}{|c|c|c|c|}
\hline & $\begin{array}{l}\text { Intermediate } \\
\text { risk PE } \\
(n=126)\end{array}$ & $\begin{array}{l}\text { Standard } \\
\text { risk PE } \\
(n=382)\end{array}$ & $p$-Value \\
\hline \multicolumn{4}{|l|}{ Demographics } \\
\hline Age, y & & & \multirow[t]{3}{*}{0.08} \\
\hline Median & 64 & 60 & \\
\hline Interquartile range & $52-74$ & $44-71$ & \\
\hline Female sex, (\%) & $56(44)$ & $163(43)$ & 0.76 \\
\hline \multicolumn{3}{|l|}{ Body weight, $\mathrm{kg}$} & \multirow[t]{3}{*}{0.07} \\
\hline Median & 86 & 80 & \\
\hline Interquartile range & $74-100$ & $68-92$ & \\
\hline $\begin{array}{l}\text { Prior history } \\
\text { of VTE (\%) }\end{array}$ & $25(20)$ & $54(14)$ & 0.16 \\
\hline \multicolumn{4}{|l|}{ VTE treatment } \\
\hline \multicolumn{4}{|l|}{$\begin{array}{l}\text { Initial treatment } \\
\text { for VTE (\%) }\end{array}$} \\
\hline LMWH & $109(87)$ & $299(78)$ & 0.05 \\
\hline UFH & $13(10)$ & $42(11)$ & 1.0 \\
\hline Rivaroxaban & $4(3)$ & $31(8)$ & 0.07 \\
\hline Apixaban & 0 & $3(<1)$ & 1.0 \\
\hline Other & 0 & $7(2)$ & 0.20 \\
\hline \multicolumn{4}{|l|}{$\begin{array}{l}\text { Maintenance } \\
\text { treatment (\%) }\end{array}$} \\
\hline Warfarin & $54(43)$ & $161(42)$ & 0.92 \\
\hline Rivaroxaban & $48(38)$ & $141(37)$ & 0.83 \\
\hline $\begin{array}{l}\text { Low molecular } \\
\text { weight heparin }\end{array}$ & $14(11)$ & $45(12)$ & 1.0 \\
\hline Apixaban & $10(8)$ & $23(6)$ & 0.53 \\
\hline No anticoagulation & 0 & $9(2)$ & 0.12 \\
\hline Dabigatran & 0 & $2(<1)$ & 1.0 \\
\hline Missing data & 0 & $1(<1)$ & 1.0 \\
\hline $\begin{array}{l}\text { Treatment duration } \\
\text { in months, median }\end{array}$ & 5.8 & 5.1 & 0.11 \\
\hline $\begin{array}{l}\text { Systemic } \\
\text { thrombolysis, (\%) }\end{array}$ & $2(1.5)$ & 0 & 0.06 \\
\hline \multicolumn{4}{|l|}{ Imaging } \\
\hline CTPA at diagnosis (\%) & $368(96)$ & $120(95)$ & 0.60 \\
\hline TTE at diagnosis (\%) & $106(28)$ & $103(82)$ & 0.0001 \\
\hline \multicolumn{4}{|l|}{ Follow-up } \\
\hline $\begin{array}{l}\text { Follow up in } \\
\text { mo (median) }\end{array}$ & 26.1 & 25.2 & 0.48 \\
\hline
\end{tabular}

Abbreviations: CTPA, computed tomographic pulmonary angiography; $\mathrm{LMWH}$, low molecular weight heparin; PE, pulmonary embolism; TTE, transthoracic echocardiogram; UFH, unfractionated heparin; VTE, venous thromboembolism.

Note: Bold values highlight statistically significant values.

Our study demonstrates that initial risk stratification is useful in predicting which patients with acute PE may be at risk of developing RV dysfunction. Importantly, we have also shown that patients with standard risk PE are still at risk of developing cardiac dysfunction, thus highlighting the need
Table 3 Study results

\begin{tabular}{|c|c|c|c|}
\hline & $\begin{array}{l}\text { Intermediate } \\
\text { risk PE } \\
(n=126)\end{array}$ & $\begin{array}{l}\text { Standard } \\
\text { risk PE } \\
(n=382)\end{array}$ & $p$-Value \\
\hline Suspected CTEPH (\%) & $2(1.6)$ & $1(0.26)$ & \multirow[t]{2}{*}{0.16} \\
\hline $\begin{array}{l}95 \% \text { confidence } \\
\text { interval, \% }\end{array}$ & $0.08-6$ & $0.01-1.6$ & \\
\hline Confirmed CTEPH & $0^{\mathrm{a}}$ & $0^{\mathrm{a}}$ & - \\
\hline $\begin{array}{l}\text { Persistent RV } \\
\text { dysfunction } \\
\text { on TTE (\%) }\end{array}$ & $16 / 36(44)$ & $15 / 84(18)$ & \multirow[t]{2}{*}{0.003} \\
\hline $\begin{array}{l}95 \% \text { confidence } \\
\text { interval, \% }\end{array}$ & $29.5-60.4$ & $11-27.5$ & \\
\hline $\begin{array}{l}\text { Residual perfusion } \\
\text { defects (\%) }\end{array}$ & $19 / 48(40)$ & $33 / 143(23)$ & \multirow[t]{2}{*}{0.04} \\
\hline $\begin{array}{l}95 \% \text { confidence } \\
\text { interval, \% }\end{array}$ & $27-53.7$ & $16.9-30.7$ & \\
\hline $\begin{array}{l}\text { Time to repeat TTE in } \\
\text { months (median) }\end{array}$ & 10.8 & 10.8 & 0.38 \\
\hline $\begin{array}{l}\text { Time to repeat } \\
\text { radiological imaging } \\
\text { in months (median) }\end{array}$ & 6.0 & 6.03 & 0.76 \\
\hline
\end{tabular}

Abbreviations: $\mathrm{CTEPH}$, chronic thromboembolism pulmonary hypertension; PE, pulmonary embolism; RV, right ventricular; TTE, transthoracic echocardiogram.

Note: Bold values highlight statistically significant values.

${ }^{a} \mathrm{CTEPH}$ unable to be confirmed as patients did not undergo right heart catheterization.

for adequate long-term monitoring and follow-up in all patients with acute PE. Further prospective research will be required to understand which molecular processes lead to either the persistence of cardiac damage, or aid in initiating the development of RV dysfunction over time.

Moreover, we have demonstrated that the diagnosis of suspected CTEPH following acute PE is infrequent, with an overall rate of diagnosis of $0.6 \%$. Previous research suggests that the size of acute thrombus impacts the development of CTEPH. ${ }^{10}$ However, to our knowledge there is no previous data comparing the impact of initial risk stratification on chronic outcomes. We have been able to show that the rate of development of CTEPH is low in both cohorts and subsequently demonstrate that initial risk stratification does not appear to impact on the development of CTEPH.

\section{Limitations}

This was a retrospective study and consequently there are some limitations to be addressed. First, there were no prespecified indications for screening for CTEPH following an acute PE. As such, decisions regarding treatment and follow-up imaging or TTE was made at the discretion of the treating clinician and thus were not uniform across study participants. Moreover, as not all patients underwent subsequent lung imaging or TTE there is the potential for selection bias to occur. We acknowledge that these issues may affect the reported rates of CTEPH in the study population but importantly clinicians would perform further 
investigations including lung imaging and TTE if patients reported persistent dyspnoea to ensure that clinically relevant findings could be explored.

Additionally, the rate of CTEPH in both populations was lower than expected. Despite showing no significant difference in rates between the PE risk groups, it is possible that this study is underpowered given the infrequent diagnosis of CTEPH. Furthermore, as previously mentioned we excluded high-risk PE from our study due to the rarity of the diagnosis and the marked increase in mortality. As high-risk PE is often associated with larger perfusion defects in conjunction with cardiac dysfunction, it is plausible that this group of patients would have higher rates of $\mathrm{CTEPH}$, but there is limited available research in this field. Given this exclusion, we cannot comment on CTEPH rates in high risk PE. However, we have been able to show that overall CTEPH rates are low in our study population and there is no role for routine screening in intermediate and standard risk PE.

Finally, the definitions for the post-PE syndrome and RV dysfunction following acute $\mathrm{PE}$ are continuing to develop and advance over time. Unlike CTEPH, there is no consensus on standardised diagnostic criteria which may lead to a delay in diagnosis. We believe that standardising the definitions of these conditions will aid in identifying patients with acute PE who are at higher risk of persistent RV dysfunction and will allow for close monitoring for development of CTEPH.

In summary, initial risk stratification following an acute PE can aid in predicting which patients may be at risk of persistent RV dysfunction. However, this does not appear to correlate with an increase in rate of CTEPH with overall rates remaining extremely low. These findings emphasize the importance of regular clinical review following an acute PE and highlight the need for prospective research in this area to identify high-risk patient groups and improve clinical outcomes.

\section{Authors' Contribution}

H.S. contributed to data collection, data analysis and manuscript preparation. W.F. contributed to data collection. W.C. contributed to data collection and manuscript review. J.B. contributed to data collection. J.M. contributed to manuscript review and oversight of research project. H.T. contributed to manuscript review and oversight of research project.

\section{Funding}

J.M. is supported by a National Health and Medical Research Council (NHMRC) Early Career Fellowship, National Heart Foundation (NHF) post-doctoral fellowship and Royal Australasian College of Physicians (RACP) Research Establishment Fellowship. H.S. is supported by Monash University Research Training Program Scholarship and Wheaton Family Scholarship.

\section{Conflict of Interest}

None declared.

\section{References}

1 Naess IA, Christiansen SC, Romundstad P, Cannegieter SC, Rosendaal FR, Hammerstrøm J. Incidence and mortality of venous thrombosis: a population-based study. J Thromb Haemost 2007;5 (04):692-699

2 Tagalakis V, Patenaude V, Kahn SR, Suissa S. Incidence of and mortality from venous thromboembolism in a real-world population: the Q-VTE Study Cohort. Am J Med 2013;126(09):832. e13-832.e21

3 Huang W, Goldberg RJ, Anderson FA, Kiefe CI, Spencer FA. Secular trends in occurrence of acute venous thromboembolism: the Worcester VTE study (1985-2009). Am J Med 2014;127(09): 829-39.e5

4 Heit JA, Silverstein MD, Mohr DN, Petterson TM, O'Fallon WM, Melton LJ III. Predictors of survival after deep vein thrombosis and pulmonary embolism: a population-based, cohort study. Arch Intern Med 1999;159(05):445-453

5 Søgaard KK, Schmidt M, Pedersen L, Horváth-Puhó E, Sørensen HT. 30-year mortality after venous thromboembolism: a population-based cohort study. Circulation 2014;130(10):829-836

6 Sista AK, Klok FA. Late outcomes of pulmonary embolism: the post-PE syndrome. Thromb Res 2018;164:157-162

7 Stevinson BG, Hernandez-Nino J, Rose G, Kline JA. Echocardiographic and functional cardiopulmonary problems 6 months after first-time pulmonary embolism in previously healthy patients. Eur Heart J 2007;28(20):2517-2524

8 Kahn SR, Hirsch AM, Akaberi A, et al. Functional and exercise limitations after a first episode of pulmonary embolism: results of the ELOPE prospective cohort study. Chest 2017;151(05): 1058-1068

9 Simonneau G, Montani D, Celermajer DS, et al. Haemodynamic definitions and updated clinical classification of pulmonary hypertension. Eur Respir J 2019;53(01):1801913

10 Pengo V, Lensing AW, Prins MH, et al; Thromboembolic Pulmonary Hypertension Study Group. Incidence of chronic thromboembolic pulmonary hypertension after pulmonary embolism. N Engl J Med 2004;350(22):2257-2264

11 Becattini C, Agnelli G, Pesavento R, et al. Incidence of chronic thromboembolic pulmonary hypertension after a first episode of pulmonary embolism. Chest 2006;130(01):172-175

12 Klok FA, van Kralingen KW, van Dijk AP, Heyning FH, Vliegen HW, Huisman MV. Prospective cardiopulmonary screening program to detect chronic thromboembolic pulmonary hypertension in patients after acute pulmonary embolism. Haematologica 2010; 95(06):970-975

13 Guérin L, Couturaud F, Parent F, et al. Prevalence of chronic thromboembolic pulmonary hypertension after acute pulmonary embolism. Prevalence of CTEPH after pulmonary embolism. Thromb Haemost 2014;112(03):598-605

14 Martí D, Gómez V, Escobar C, et al. Incidence of symptomatic and asymptomatic chronic thromboembolic pulmonary hypertension [in Spanish]. Arch Bronconeumol 2010;46(12):628-633

15 Poli D, Grifoni E, Antonucci E, et al. Incidence of recurrent venous thromboembolism and of chronic thromboembolic pulmonary hypertension in patients after a first episode of pulmonary embolism. J Thromb Thrombolysis 2010;30(03):294-299

16 Korkmaz A, Ozlu T, Ozsu S, Kazaz Z, Bulbul Y. Long-term outcomes in acute pulmonary thromboembolism: the incidence of chronic thromboembolic pulmonary hypertension and associated risk factors. Clin Appl Thromb Hemost 2012;18(03):281-288

17 Wolf M, Boyer-Neumann C, Parent F, et al. Thrombotic risk factors in pulmonary hypertension. Eur Respir J 2000;15(02):395-399

18 Bonderman D, Jakowitsch J, Adlbrecht C, et al. Medical conditions increasing the risk of chronic thromboembolic pulmonary hypertension. Thromb Haemost 2005;93(03):512-516 
19 Bonderman D, Wilkens H, Wakounig S, et al. Risk factors for chronic thromboembolic pulmonary hypertension. Eur Respir J 2009;33(02):325-331

20 Taboada D, Pepke-Zaba J, Jenkins DP, et al. Outcome of pulmonary endarterectomy in symptomatic chronic thromboembolic disease. Eur Respir J 2014;44(06):1635-1645

21 Olgun Yıldızeli Ş, Kepez A, Taş S, et al. Pulmonary endarterectomy for patients with chronic thromboembolic disease. Anatol J Cardiol 2018;19(04):273-278

22 Riedel M, Stanek V, Widimsky J, Prerovsky I. Longterm follow-up of patients with pulmonary thromboembolism. Late prognosis and evolution of hemodynamic and respiratory data. Chest 1982; 81(02):151-158

23 Konstantinides SV, Torbicki A, Agnelli G, et al; Task Force for the Diagnosis and Management of Acute Pulmonary Embolism of the European Society of Cardiology (ESC) 2014 ESC guidelines on the diagnosis and management of acute pulmonary embolism. Eur Heart J 2014;35(43):3033-3069, 3069a-3069k

24 Lang RM, Badano LP, Mor-Avi V, et al. Recommendations for cardiac chamber quantification by echocardiography in adults: an update from the American Society of Echocardiography and the European Association of Cardiovascular Imaging. J Am Soc Echocardiogr 2015;28(01):1-39.e14

25 Galiè N, Humbert M, Vachiery JL, et al; ESC Scientific Document Group 2015 ESC/ERS Guidelines for the diagnosis and treatment of pulmonary hypertension: the Joint Task Force for the Diagnosis and Treatment of Pulmonary Hypertension of the European Society of Cardiology (ESC) and the European Respiratory Society (ERS): Endorsed by: Association for European Paediatric and Congenital Cardiology (AEPC), International Society for Heart and Lung Transplantation (ISHLT). Eur Heart J 2016;37(01): $67-119$

26 Konstantinides SV, Vicaut E, Danays T, et al. Impact of thrombolytic therapy on the long-term outcome of intermediate-risk pulmonary embolism. J Am Coll Cardiol 2017;69(12):1536-1544

27 Barco S, Russo M, Vicaut E, et al. Incomplete echocardiographic recovery at 6 months predicts long-term sequelae after intermediate-risk pulmonary embolism. A post-hoc analysis of the Pulmonary Embolism Thrombolysis (PEITHO) trial. Clin Res Cardiol 2019;108(07):772-778 